\title{
MicroRNA-223 affects IL-6 secretion in mast cells via the IGF1R/PI3K signaling pathway
}

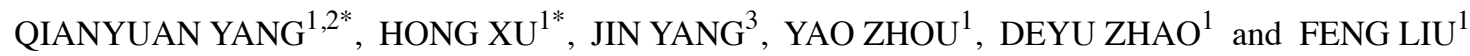 \\ ${ }^{1}$ Department of Respiratory Medicine, Nanjing Children's Hospital Affiliated to Nanjing Medical University, \\ Nanjing, Jiangsu 210008; ${ }^{2}$ Department of Pediatrics, Changzhou No. 2 People's Hospital Affiliated with \\ Nanjing Medical University, Changzhou, Jiangsu 213000; ${ }^{3}$ Department of Pediatrics, \\ Jiangsu Huai'an Maternity and Children's Hospital, Huai'an, Jiangsu 223002, P.R. China
}

Received July 29, 2015; Accepted May 18, 2016

DOI: $10.3892 / \mathrm{ijmm} .2016 .2649$

\begin{abstract}
In this study, we aimed to assess the effects of microRNA-223 (miR-223) on interleukin-6 (IL-6) secretion in mast cells and determine the underlying molecular mechanisms. Mast cells (P815) were transfected with miR-223 lentiviral vector and miR-223 inhibitor. miR-223 expression was then evaluated using reverse transcription-quantitative PCR (RT-qPCR). IL-6 levels in the supernatant were analyzed using enzyme-linked immunosorbent assay. The signaling pathways in mast cells with downregulated miR-223 were initially evaluated by gene chip. Downregulation of miR-223 and its target gene was tested using a luciferase reporter assay. The expression of phosphate-AKT (p-AKT) and its target protein insulin-like growth factor-1 receptor (IGF1R) was assessed by western blot analysis. Phosphatidylinositol 3-kinase (PI3K)-inhibitor (LY294002) and insulin-like growth factor-1 (IGF1) were used to determine the effect of miR-223 on IL-6 secretion in mast cells. The results showed that microRNA-223 reduced IL-6 concentration in the mast cells. The gene chip results predicted an induction of the PI3K-AKT signaling pathway in the mast cells. Luciferase reporter assay confirmed IGFIR gene to be a target of miR-223. The p-AKT and IGF1R levels increased following miR-223 downregulation in mast cells. In addition, the specific PI3K-inhibitor LY294002 decreased IL-6 secretion. Incubation with IGF1 resulted in the induction of IL-6 secretion in miR-223-expressing mast cells. In conclusion, it was shown that miR-223 reduces IL- 6 secretion in mast cells by inhibiting the IGF1R/PI3K signaling pathway.
\end{abstract}

Correspondence to: Professor Deyu Zhao or Dr Feng Liu, Department of Respiratory Medicine, Nanjing Children's Hospital Affiliated to Nanjing Medical University, 72 Guangzhou Road, Nanjing, Jiangsu 210008, P.R. China

E-mail: zhaodeyu988@126.com

E-mail: axsliu@163.com

*Contributed equally

Key words: mast cells, microRNA-223, insulin-like growth factor-1 receptor, phosphatidylinositol 3-kinase, interleukin-6 secretion

\section{Introduction}

Allergic inflammation is accompanied by the coordinated expression of a number of genes and proteins that initiate, sustain, and propagate immune responses and tissue remodeling (1). Mast cells are immune cells of hematopoietic origin that contribute to host defense mechanisms through the receptor-mediated release of inflammatory mediators (2), as well as the inflammatory reactions associated with allergic disorders such as asthma and anaphylaxis $(3,4)$. IgE-mediated degranulation and cytokine production by mast cells were shown to be reduced by piperine through the inhibition of Lyn, p38, extracellular signal-regulated kinase (ERK), and Ras phosphorylation (5). FceRI-MCs release TNF- $\alpha$ and interleukin-6 (IL-6), which trigger anaphylaxis and mediate the symptoms and tissue effects of chronic atopic disorders (6). Mast cells were shown to be increased in the asthmatic airways, followed by IL-6 release (7).

IL-6 is a pleiotropic cytokine involved in the regulation of inflammatory and immunological responses, acute phase protein production, and hematopoiesis (8). Serum sIL-6R levels are increased in asthma patients (9), indicating the likely involvement of IL-6 in the pathogenesis of allergic inflammation. Pre-incubation of mast cells with IL-6 can significantly upregulate the IgE-mediated histamine release (10). Such observations indicated that IL-6 has a close relationship with mast cell-mediated inflammation. Regulation of inflammatory responses is ensured by coordinated control of the gene expression in participating immune system and tissue cells. A class of short single-stranded RNA molecules termed microRNAs (miRNAs or miRs) have been demonstrated to be involved in the regulation of inflammatory responses (11).

miRNAs constitute a large family of small non-coding RNAs that have emerged as key post-transcriptional regulators in a wide variety of organisms (12). Previous findings demonstrated the associations of miRNAs with many types of inflammatory state. Upregulation of miRNA-221 has been detected in lung biopsy specimens in an OVA-induced murine asthma model, whereas the inhibition of miR-221 reduced airway inflammation (13).

miR-223 was first identified bioinformatically and subsequently characterized in the hematopoietic system, where it is specifically expressed in the myeloid compartment $(14,15)$. miR-223 is fairly specific to the hematopoietic lineage, where 
it limits inflammation and prevents collateral damage during infection (16). Previous studies have reported that miR-223 can regulate neutrophil activity and inflammation (17). The downregulation of miR-223 was shown to promote IL-6 and IL-1 $\beta$ expression in macrophages (18). It is clear that miR-223 is important in inhibiting the development of inflammatory cells; however, miR-223 function in mast cells remains unclear. The present study aimed to examine the relationship between miR-223 and inflammation in mast cells, and determine the underlying molecular mechanisms.

\section{Materials and methods}

Reagents. Dulbecco's modified Eagle's medium (DMEM) and fetal bovine serum (FBS) were purchased from Gibco-BRL (Grand Island, NY, USA). LY294002 and Cell Counting Kit-8 (CCK-8) were obtained from Sigma-Aldrich (St. Louis, MO, USA). The mouse IL-6 immunoassay kit was obtained from R\&D Systems, Inc. (Minneapolis, MN, USA). Specific monoclonal antibodies against AKT (\#9272) and phosphorylated-AKT (p-AKT; \#4060) were purchased from Cell Signaling Technology, Inc. (Beverly, MA, USA). Specific polyclonal antibodies against insulin-like growth factor-1 receptor (IGF1R; sc-713) and GAPDH (sc-25778) were purchased from Santa Cruz Biotechnology, Inc. (Dallas, TX, USA). The secondary antibody, goat anti-rabbit IgG-HRP (sc-2004) was also obtained from Santa Cruz Biotechnology, Inc.

Cell culture and transfection. Mast cells purchased from the Shanghai Institute of Cell Library (Shanghai, China) were cultured in DMEM supplemented with $10 \%$ FBS, $100 \mathrm{U} / \mathrm{ml}$ penicillin, and $100 \mathrm{U} / \mathrm{ml}$ streptomycin at $37^{\circ} \mathrm{C}$ in $5 \% \mathrm{CO}_{2}$. The cells were transfected with miR-223 lentiviral vector or miR-223 inhibitor using the Lipofectamine 2000 reagent (Invitrogen Life Technologies, Carlsbad, CA, USA) followed by $48 \mathrm{~h}$ of culture. Supernatants and cells were then rinsed with ice-cold PBS and cells were collected for subsequent analysis.

RNA extraction and reverse transcription-quantitative $P C R(R T-q P C R)$. Total RNA was isolated from mast cells using TRIzol reagent (Invitrogen Life Technologies). Total RNA (200 ng) from each specimen was used for primerspecific reverse transcription (RT). RT was performed using the TaqMan MicroRNA Reverse Transcription kit, according to the manufacturer's instructions (Applied Biosystems Life Technologies, Foster City, CA, USA). The cDNA samples were used for quantitative PCR, according the TaqMan MicroRNA assay kit manufacturer instructions (Applied Biosystems Life Technologies). Data were analyzed by the $2^{-\Delta \Delta \mathrm{Ct}}$ method.

Enzyme-linked immunosorbent assay (ELISA). IL-6 amounts were measured using ELISA kits from R\&D Systems, Inc., according to the manufacturer's instructions. IL-6 levels were expressed as a ratio of IL- 6 amounts to cell number.

Microarray analysis. To identify the possible changes in the signaling pathways following miR-223 expression, the cells were divided into the blank control and miR-223 knockdown groups and subjected to microarray analysis (Kangchen Bio-tech Inc., Shanghai, China), as previously described (19).

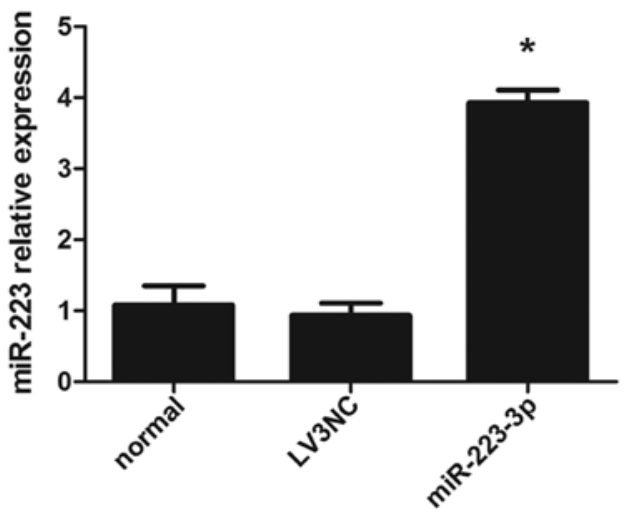

Figure 1. Expression of microRNA-223 (miR-223) in mast cells. After the transfection of miR-223 expression of lentiviral vectors in mast (P815) cells, the relative level of miR-223 was higher after transfection with lentiviral vector into mast cells, compared with the negative control and blank control group, $(\mathrm{p}<0.05)$. Data are mean $\pm \mathrm{SD}(\mathrm{n}=6)$ of three independent experiments. Analysis was performed using the Student's t-test, ${ }^{*} \mathrm{p}<0.05$.

Luciferase reporter assay. Mast cells were seeded in 24-well tissue culture plates the day prior to transfection. miR-223-3p mimics (mimics NC as control group) and IGFR-1-3'UTR vector in luciferase reporter vector were transiently co-transfected into cells. After $48 \mathrm{~h}$, the cells were lysed and luciferase activity was detected with the Dual Luciferase Reporter Assay kit (Promega Corp., Madison, WI, USA) to validate the role of miRNA target gene in inhibiting translation.

Western blotting. Total protein $(50 \mu \mathrm{g})$ from each sample was separated by $10 \%$ sodium dodecyl sulfate-polyacrylamide gel electrophoresis, and transferred onto nitrocellulose membranes. The membranes were blocked with 5\% non-fat milk for $1 \mathrm{~h}$ at room temperature $\left(20^{\circ} \mathrm{C}\right)$ and probed with the corresponding primary antibodies overnight at $4^{\circ} \mathrm{C}$. After three washes with TBST, the membranes were incubated with horseradish peroxidase-conjugated secondary antibody at room temperature $\left(20^{\circ} \mathrm{C}\right)$ for $2 \mathrm{~h}$. Proteins were detected using the enhanced chemiluminescence detection system (Bio-Rad, Hercules, CA, USA). Bands were captured by the Image Lab system (Bio-Rad) and their densities were analyzed after normalization by GAPDH levels.

Statistical analysis. Statistical analysis was performed using the SPSS software (SPSS 20.0; Chicago, IL, USA). Data were presented as mean \pm standard deviation (SD) from at least three independent experiments. The Student's t-test was used to analyze the differences between two groups. $\mathrm{P}<0.05$ was considered statistically significant.

\section{Results}

Overexpression of miR-223 in mast cells. To assess the effect of miR-223 on IL-6 expression in mast cells, the cells were transfected with miR-223 lentiviral vector and miR-223 expression was detected by RT-qPCR. As expected, miR-223 levels were higher following transfection with lentiviral vector into mast cells, compared with the negative control and blank control group (Fig. 1). 


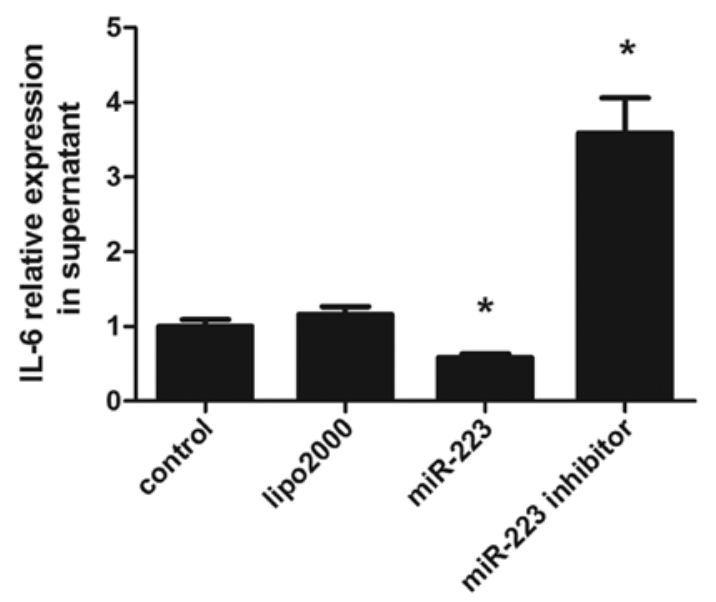

Figure 2. Effects of microRNA-223 (miR-223) on IL-6 expression. miR-223 inhibited IL-6 secretion in the miR-223 overexpression group (compared with the control group, $\mathrm{p}<0.05)$, while the downregulation of miR-223 increased IL-6 concentrations (compared with the control group, $\mathrm{p}<0.05$ ) Data are mean $\pm S D(n=6)$ of three independent experiments. Analysis was performed using the Student's t-test, "p $<0.05$.

Overexpression of miR-223 inhibits IL-6 secretion. IL-6 is a multifunctional cytokine produced by a wide variety of cells and plays vital roles in immunological responses, hematopoiesis, host defense, and acute phase reaction (20). The involvement of miR-223 has been demonstrated in various types of cancer, inflammatory diseases, autoimmune diseases and other pathological processes (21). Following the transfection of miR-223 lentiviral vector into mast cells, the cells were cultured for $48 \mathrm{~h}$, and the supernatants were collected for IL-6 detection by ELISA. Overexpression of miR-223 suppressed IL-6 secretion, while miR-223 downregulation resulted in increased IL-6 levels (Fig. 2).

Changes in signaling pathways in mast cells differentially expressing miR-223. After transfection of miR-223 lentiviral vector into mast cells, miR-223 markedly altered the phosphatidylinositol 3-kinase (PI3K)-AKT signaling pathway as assessed by gene chip, bioinformatics analysis and pathway analysis. Conversely, this pathway was activated by miR-223 downregulation. These findings indicate that the main function of miR-223 may be associated with cytokine secretion in mast cells. According to the gene chip and pathway analysis, miR-223 regulated IL-6 secretion via IGF1R/PI3K signaling in mast cells (Fig. 3).

Luciferase reporter assay and western blot analysis confirm $I G F 1 R$ as a target gene of $m i R-223$. According to our gene chip data and bioinformatics analysis, IGF1R was a target gene of miR-223 in mast cells. To assess whether miR-223 directly affects IGF1R, luciferase reporter technology was used. As shown in Fig. 4A, IGF1R was confirmed as a target gene of miR-223 in mast cells. In addition, IGF1R levels were detected in experimental and control groups by western blotting. The results showed reduced IGF1R expression in cells overexpressing miR-223, whereas the downregulation of miR-223 produced the opposite effects (Fig. 4B).

IGF-1 promotes IL-6 secretion following the upregulation of miR-223 in mast cells. Luciferase reporter gene and western blot analysis confirmed IGF1R as a target gene of miR-223.
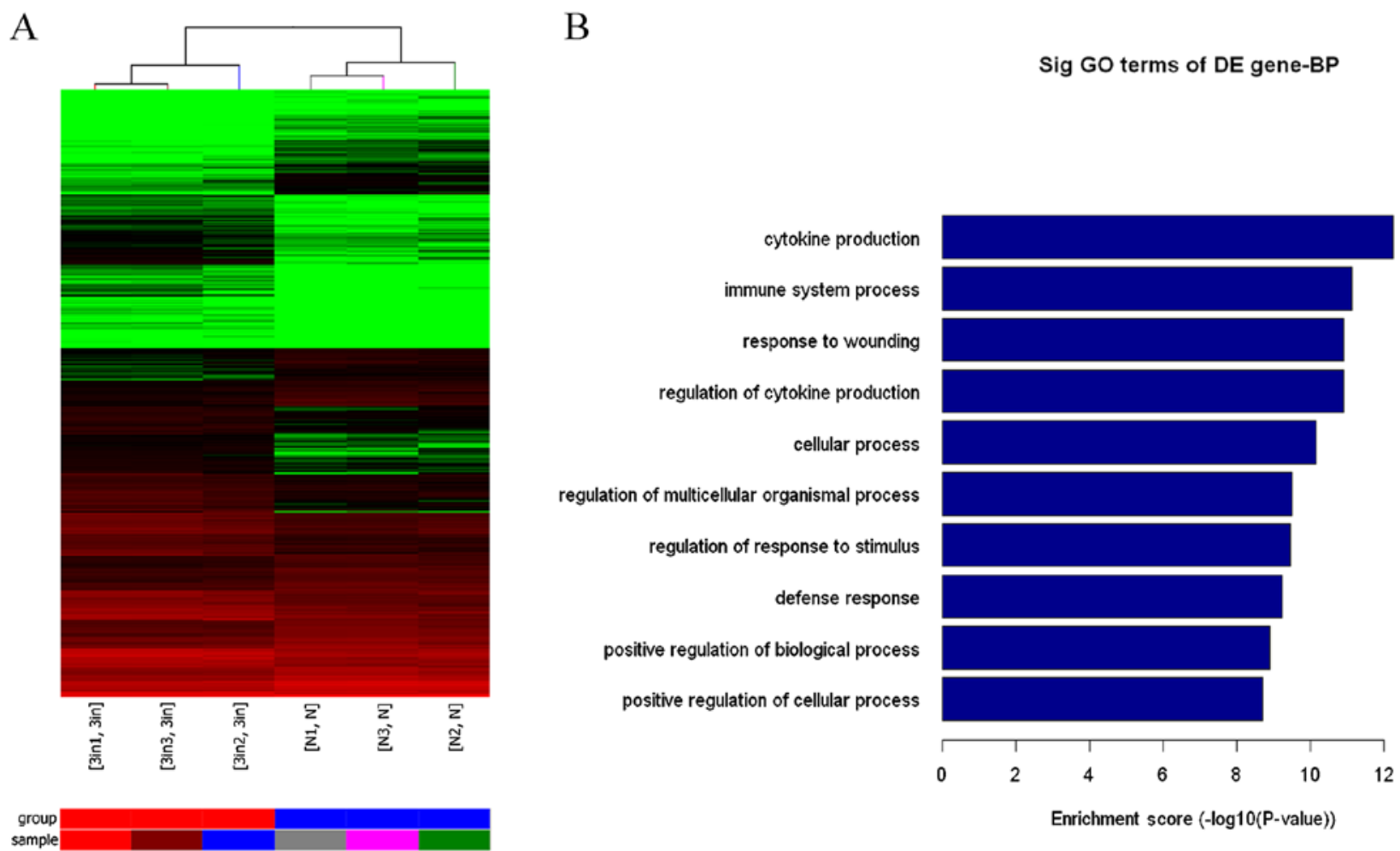

Figure 3. (A) Heat map of differentially expressed genes between microRNA-223 (miR-223) and blank control groups (p<0.05, n=3). (B) Gene ontology analysis showed that the main differences were associated with cytokine production $(\mathrm{p}<0.05, \mathrm{n}=3)$. 
A

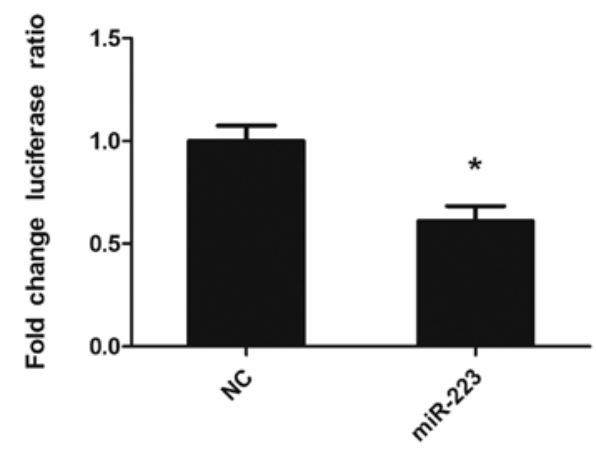

B

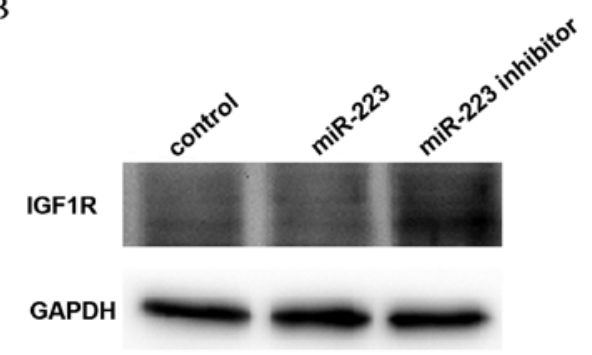

Figure 4. MicroRNA-223 (miR-223) reduces insulin-like growth factor-1 receptor (IGF1R) protein expression in mast cells. Luciferase reporter gene confirms IGF1R as a target gene of miR-223 in mast cells. (A) Compared with the control group (NC), the luciferase ratio was significantly reduced in the miR-223 group ( $\mathrm{p}<0.05, \mathrm{n}=4)$. (B) IGF1R protein levels in mast cells trnsfected with miR-223 lentiviral vector or miR-223 inhibitor were assessed by western blotting. Data are representative of three separate experiments.

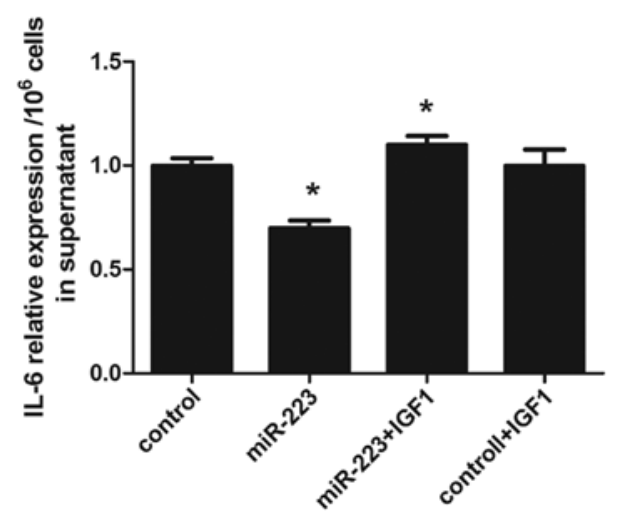

Figure 5. Effects of insulin-like growth factor-1 (IGF1) on IL-6 expression. Mast cells $\left(1 \times 10^{5}\right.$ cells $\left./ \mathrm{ml}\right)$ were incubated with IGF-1 for $36 \mathrm{~h}$, and IL-6 secretion in supernatants was detected. IL- 6 expression was reduced in the miR-223 group (compared with the control group, $\mathrm{p}<0.05$ ). When mast cells transfected with microRNA-223 (miR-223) were incubated with IGF1, IL-6 concentrations increased (compared with the miR-223 group, $\mathrm{p}<0.05$ ). Data are mean $\pm \mathrm{SD}(\mathrm{n}=6)$ of three independent experiments. Analysis was performed using the Student's t-test, ${ }^{*} \mathrm{p}<0.05$.

Thus, mast cells were transfected with insulin-like growth factor-1 (IGF1), and IL-6 secretion was subsequently assessed using ELISA. It was found that incubation with IGF-1 reversed the IL- 6 concentration decrease caused by miR-223 in mast cells (Fig. 5).

miR-223 inhibits the PI3K-AKT signaling pathway in mast cells. Since miR-223 suppressed IGF1R expression, we assessed whether the IGF1R-mediated downstream signaling

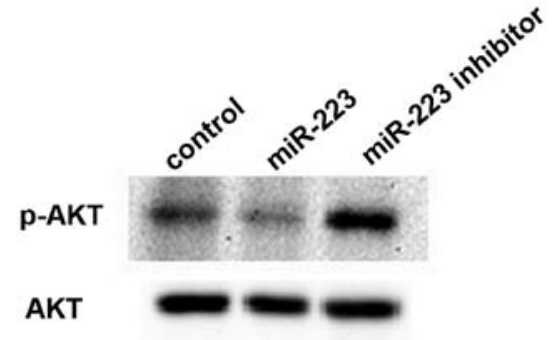

Figure 6. MicroRNA-223 (miR-223) affects the function of mast cells through the phatidylinositol 3-kinase (PI3K)-AKT signaling pathway. p-AKT protein levels in mast cells transfected with miR-223 lentiviral vector or miR-223 inhibitor as assessed by western blotting. Data are representative of three separate experiments.

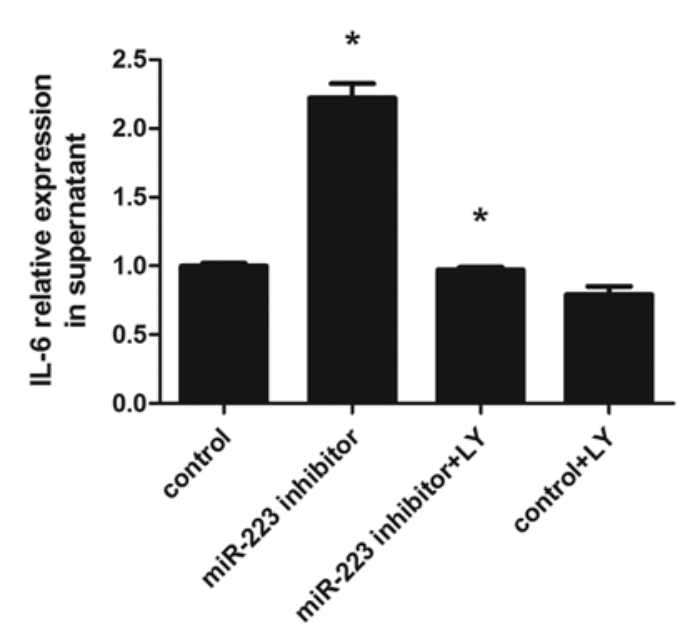

Figure 7. Effects of LY294002 on IL-6 secretion. Mast cells ( $1 \times 10^{5}$ cells $\left./ \mathrm{ml}\right)$ were incubated with LY294002 $(20 \mu \mathrm{M}) 30$ min prior to treatment with $500 \mathrm{ng} / \mathrm{ml} \mathrm{LPS}$ for $6 \mathrm{~h}$, and supernatants collected. In normal and normal+LY group, LY294002 reduces IL-6 secretion $(\mathrm{p}<0.05)$. Compared with the microRNA-223 (miR-223) inhibitor group, IL-6 expression was reduced in the miR-223 inhibitor+LY294002 group ( $\mathrm{p}<0.05)$. However, IL-6 secretion in the normal and miR-223 inhibitor+LY groups showed no statistically significant difference. Data are mean $\pm S D(n=6)$ of three independent experiments. Analysis was performed using the Student's t-test, ${ }^{*} \mathrm{p}<0.05$.

pathway was also affected by miR-223. Gene chip and pathway analysis predicted that PI3K-AKT signaling was negatively regulated by miR-223 in mast cells. The expression levels of AKT, an essential protein kinase in the PI3K-AKT pathway downstream of IGF1R, and its phosphorylated form p-AKT were evaluated by western blotting. We found that total AKT protein levels were similar in the three groups. However, phosphorylated AKT protein levels were reduced after the downregulation of miR-223 and increased after the miR-223 upregulation compared with the control group (Fig. 6).

Specific PI3K-inhibitor LY294002 decreases IL-6 concentration. PI3K activity is essential for the differentiation of mast cells, as well as their long-term survival and function (22). PI3K inhibitors, including wortmannin and LY294002, have been widely reported to inhibit antigen-mediated degranulation and cytokine production in rodent and human mast cells (23-25). To investigate whether the PI3K-AKT signaling pathway plays a role in IL-6 secretion, the specific PI3K-inhibitor LY294002 was used to treat control cells and those with silenced miR-223: 
cells were incubated with LY294002 for 30 min prior to treatment with LPS for $6 \mathrm{~h}$. Subsequently, IL-6 secretion in the supernatants was detected by ELISA. As shown in Fig. 7, LY294002 blocked the PI3K-AKT signaling pathway and reversed IL-6 induction by suppressing miR-223 in mast cells.

\section{Discussion}

It has been demonstrated that miR-223 targets leukemia fusion protein, providing the evidence for a link between epigenetic silencing of a miRNA locus and the differentiation block of myeloid precursors (26). In the present study, miR-223 was identified as an important modulator of IL- 6 secretion in mast cells. Previous studies have reported the vital role of mast cells in inflammatory reactions. MC-derived IL-10 was also shown to reduce $\mathrm{B}$-cell responses and antibody production (27). miR-155 expression enhances FceRI degranulation and the release of TNF $\alpha$, IL-6, and IL-13 in relation to the activity of the PI3K/AKT pathway in mast cells (28). Sporothrix schenckii yeasts were shown to induce TNF- $\alpha$ and IL- 6 release, and activate the ERK signaling pathway in mast cells (29).

In the present study, miR-223 was involved in the regulation of cytokine secretion in mast cells. The relevant role of miR-223 in the process was testified by the overexpression and knockdown experiments. Upregulation of miR-223 in mast cells resulted in reduced IL-6 secretion, while its downregulation increased IL- 6 expression. From the perspective of inflammatory responses, miRNAs have recently been shown to be expressed in immune cells and to target proteins involved in inflammation regulation, consequently affecting the magnitude of the response (30). For instance, miR-146a is involved in the regulation of endothelial cell inflammation via the modulation of Nox4 expression in a diabetic atherothrombosis model (31). In addition, miR-155 was shown to contribute to regulating inflammation of allergic airway by modulating TH2 responses through the transcription factor PU.1 (32).

Based on previous studies, an increased number of molecular mechanisms of the miR-223 effect in mast cells have been revealed $(33,34,37)$. Gene chip and bioinformatics analysis predicted IGF1R as a target gene of miR-223, and that the PI3K-AKT signaling pathway was decreased in mast cells. Subsequently IGF1R was confirmed as a miR-223 target using luciferase assay reporter. Overexpression of miR-223 in mast cells resulted in decreased IGF1R and $\mathrm{p}-\mathrm{AKT}$ protein levels compared to control cells, while silencing miR-223 in mast cells increased IGF1R and p-AKT protein expression. It is now recognised that miRNAs exert their function of fine modulators of gene expression by controlling translational efficiency of a large number of target genes (35). It has been shown that miR-223 targets NLRP3, and can prevent its early translation in the myeloid lineage (36). In addition, miR-223 targets FBXW7/hCdc4 expression at the post-transcriptional level and appears to regulate cell apoptosis, proliferation, and invasion in gastric cancer (37).

The results of the present study showed that miR-223 may regulate IL-6 levels via IGF1R/PI3K signaling in mast cells. Similarly, the PI3K inhibitor LY294002 blocked AKT phosphorylation and reversed the induction of IL-6 secretion caused by miR-223 knockdown in mast cells. When mast cells were incubated with IGF1, IL-6 levels significantly increased compared with the control cells. The PI3K-AKT signaling pathway has been previously demonstrated to have a close relationship with inflammation. This association has been well studied in various tumors and inflammatory diseases. Overexpression of miR-223 during the dextran sulfate sodium (DSS)-induced mouse model of colitisassociated tumor growth inhibited AKT phosphorylation and IGF-1R expression (38). The upregulated expression of WNT5a in PCOS was shown to increase inflammation and oxidative stress predominantly via the PI3K/AKT signaling pathway (39). B-type natriuretic peptide post-conditioning also significantly inhibited a TNF- $\alpha$ and IL- 6 level increase through the PI3K/AKT signaling pathway (40).

In conclusion, miR-223 decreased IL- 6 secretion in mast cells. Additionally, IGF1R, as a target gene of miR-223, and the PI3K signaling pathway, are involved in the regulation of mast cells by miR-223.

\section{Acknowledgements}

The present study was supported by grants from the National Natural Science Foundation of China (no. 81200012, awarded to F. L.) and the National Natural Science Foundation of China (no. 81370132, awarded to D. Z.).

\section{References}

1. Lu TX and Rothenberg ME: Diagnostic, functional, and therapeutic roles of microRNA in allergic diseases. J Allergy Clin Immunol 132: 3-13, quiz 14, 2013.

2. Galli SJ and Tsai M: Mast cells in allergy and infection: versatile effector and regulatory cells in innate and adaptive immunity. Eur J Immunol 40: 1843-1851, 2010.

3. Mekori YA and Metcalfe DD: Mast cells in innate immunity. Immunol Rev 173: 131-140, 2000.

4. Brown JM, Wilson TM and Metcalfe DD: The mast cell and allergic diseases: role in pathogenesis and implications for therapy. Clin Exp Allergy 38: 4-18, 2008.

5. Huang J, Zhang T, Han S, Cao J, Chen Q and Wang S: The inhibitory effect of piperine from Fructus piperis extract on the degranulation of RBL-2H3 cells. Fitoterapia 99: 218-226, 2014.

6. Sumpter TL, Ho CH, Pleet AR, Tkacheva OA, Shufesky WJ, Rojas-Canales DM, Morelli AE and Larregina AT: Autocrine hemokinin-1 functions as an endogenous adjuvant for IgE-mediated mast cell inflammatory responses. J Allergy Clin Immunol 135: 1019-1030, 2014.

7. Bradding P, Roberts JA, Britten KM, Montefort S, Djukanovic R, Mueller R, Heusser $\mathrm{CH}$, Howarth $\mathrm{PH}$ and Holgate ST: Interleukin- $4,-5$, and -6 and tumor necrosis factor-alpha in normal and asthmatic airways: Evidence for the human mast cell as a source of these cytokines. Am J Respir Cell Mol Biol 10: 471-480, 1994.

8. Molina-Holgado E and Molina-Holgado F: Mending the broken brain: Neuroimmune interactions in neurogenesis. J Neurochem 114: 1277-1290, 2010.

9. Yokoyama A, Kohno N, Sakai K, Kondo K, Hirasawa Y and Hiwada K: Circulating levels of soluble interleukin-6 receptor in patients with bronchial asthma. Am J Respir Crit Care Med 156: 1688-1691, 1997.

10. Yanagida M, Fukamachi H, Ohgami K, Kuwaki T, Ishii H, Uzumaki H, Amano K, Tokiwa T, Mitsui H, Saito $\mathrm{H}$, et al: Effects of T-helper 2-type cytokines, interleukin-3 (IL-3), IL-4, IL-5, and IL-6 on the survival of cultured human mast cells. Blood 86: 3705-3714, 1995.

11. Rebane A and Akdis CA: MicroRNAs: Essential players in the regulation of inflammation. J Allergy Clin Immunol 132: 15-26, 2013.

12. Mayoral RJ, Pipkin ME, Pachkov M, van Nimwegen E, Rao A and Monticelli S: MicroRNA-221-222 regulate the cell cycle in mast cells. J Immunol 182: 433-445, 2009. 
13. Qin HB, Xu B, Mei JJ, Li D, Liu JJ, Zhao DY and Liu F: Inhibition of miRNA-221 suppresses the airway inflammation in asthma. Inflammation 35: 1595-1599, 2012.

14. Chen CZ, Li L, Lodish HF and Bartel DP: MicroRNAs modulate hematopoietic lineage differentiation. Science 303: 83-86, 2004.

15. Lim LP, Glasner ME, Yekta S, Burge CB and Bartel DP: Vertebrate microRNA genes. Science 299: 1540, 2003.

16. Haneklaus M, Gerlic M, O'Neill LA and Masters SL: miR-223: infection, inflammation and cancer. J Intern Med 274: 215-226, 2013.

17. Johnnidis JB, Harris MH, Wheeler RT, Stehling-Sun S, Lam MH, Kirak O, Brummelkamp TR, Fleming MD and Camargo FD: Regulation of progenitor cell proliferation and granulocyte function by microRNA-223. Nature 451: 1125-1129, 2008.

18. Chen Q, Wang H, Liu Y, Song Y, Lai L, Han Q, Cao X and Wang Q: Inducible microRNA-223 down-regulation promotes TLR-triggered IL- 6 and IL-1 $\beta$ production in macrophages by targeting STAT3. PLoS One 7: e42971, 2012.

19. Zhou Y, Yang J, Deng H, Xu H, Zhang J, Jin W, Gao H, Liu F and Zhao D: Respiratory syncytial virus infection modulates interleukin 8 production in respiratory epithelial cells through a transcription factor activator protein 1 signaling pathway. Mol Med Rep 10: 1443-1447, 2014.

20. Akira S and Kishimoto T: IL-6 and NF-IL6 in acute-phase response and viral infection. Immunol Rev 127: 25-50, 1992.

21. Taïbi F, Metzinger-Le Meuth V, Massy ZA and Metzinger L: miR-223: an inflammatory oncomiR enters the cardiovascular field. Biochim Biophys Acta 1842: 1001-1009, 2014.

22. Kim MS, Rådinger M and Gilfillan AM: The multiple roles of phosphoinositide 3-kinase in mast cell biology. Trends Immunol 29: 493-501, 2008.

23. Kim MS, Kuehn HS, Metcalfe DD and Gilfillan AM: Activation and function of the mTORC1 pathway in mast cells. J Immunol 180: 4586-4595, 2008.

24. Okayama Y, Tkaczyk C, Metcalfe DD and Gilfillan AM: Comparison of Fc epsilon RI- and Fc gamma RI-mediated degranulation and TNF-alpha synthesis in human mast cells: Selective utilization of phosphatidylinositol-3-kinase for $\mathrm{Fc}$ gamma RI-induced degranulation. Eur J Immunol 33: 1450-1459, 2003.

25. Tkaczyk C, Beaven MA, Brachman SM, Metcalfe DD and Gilfillan AM: The phospholipase C gamma 1-dependent pathway of Fc epsilon RI-mediated mast cell activation is regulated independently of phosphatidylinositol 3-kinase. J Biol Chem 278: 48474-48484, 2003.

26. Fazi F, Racanicchi S, Zardo G, Starnes LM, Mancini M, Travaglini L, Diverio D, Ammatuna E, Cimino G, Lo-Coco F, et al: Epigenetic silencing of the myelopoiesis regulator microRNA-223 by the AML1/ETO oncoprotein. Cancer Cell 12: 457-466, 2007.

27. Chacón-Salinas R, Limón-Flores AY, Chávez-Blanco AD, Gonzalez-Estrada A and Ullrich SE: Mast cell-derived IL-10 suppresses germinal center formation by affecting $\mathrm{T}$ follicular helper cell function. J Immunol 186: 25-31, 2011.
28. Biethahn K, Orinska Z, Vigorito E, Goyeneche-Patino DA, Mirghomizadeh F, Föger N and Bulfone-Paus S: miRNA-155 controls mast cell activation by regulating the PI3K $\gamma$ pathway and anaphylaxis in a mouse model. Allergy 69: 752-762, 2014.

29. Romo-Lozano Y, Hernández-Hernández F and Salinas E: Sporothrix schenckii yeasts induce ERK pathway activation and secretion of IL- 6 and TNF- $\alpha$ in rat mast cells, but no degranulation. Med Mycol 52: 862-868, 2014.

30. O'Neill LA, Sheedy FJ and McCoy CE: MicroRNAs: the fine-tuners of Toll-like receptor signalling. Nat Rev Immunol 11: 163-175, 2011.

31. Wang HJ, Huang YL, Shih YY, Wu HY, Peng CT and Lo WY: MicroRNA-146a decreases high glucose/thrombin-induced endothelial inflammation by inhibiting NAPDH oxidase 4 expression. Mediators Inflamm 2014: 379537, 2014.

32. Malmhall C, Alawieh S, Lu Y, Sjöstrand M, Bossios A, Eldh M and Rådinger M: MicroRNA-155 is essential for $\mathrm{T}_{\mathrm{H}} 2$-mediated allergen-induced eosinophilic inflammation in the lung. J Allergy Clin Immunol 133: 1429-1438, 1438.e1421-1427, 2014.

33. Wu L, Li H, Jia CY, Cheng W, Yu M, Peng M, Zhu Y, Zhao Q, Dong YW, Shao K, et al: MicroRNA-223 regulates FOXO1 expression and cell proliferation. FEBS Lett 586: 1038-1043, 2012.

34. Wang Q, Zhao DY, Xu H, Zhou H, Yang QY, Liu F and Zhou GP: Down-regulation of microRNA-223 promotes degranulation via the PI3K/Akt pathway by targeting IGF-1R in mast cells. PLoS One 10: e0123575, 2015.

35. Bartel DP: MicroRNAs: genomics, biogenesis, mechanism, and function. Cell 116: 281-297, 2004.

36. Bauernfeind F, Rieger A, Schildberg FA, Knolle PA, Schmid-Burgk JL and Hornung V: NLRP3 inflammasome activity is negatively controlled by miR-223. J Immunol 189: 4175-4181, 2012.

37. Li J, Guo Y, Liang X, Sun M, Wang G, De W and Wu W: MicroRNA-223 functions as an oncogene in human gastric cancer by targeting FBXW7/hCdc4. J Cancer Res Clin Oncol 138: 763-774, 2012.

38. Josse C, Bouznad N, Geurts P, Irrthum A, Huynh-Thu VA, Servais L, Hego A, Delvenne P, Bours V and Oury C: Identification of a microRNA landscape targeting the PI3K/ Akt signaling pathway in inflammation-induced colorectal carcinogenesis. Am J Physiol Gastrointest Liver Physiol 306: G229-G243, 2014

39. Zhao Y, Zhang C, Huang Y, Yu Y, Li R, Li M, Liu N, Liu P and Qiao J: Up-regulated expression of WNT5a increases inflammation and oxidative stress via $\mathrm{PI} 3 \mathrm{~K} / \mathrm{AKT} / \mathrm{NF}-\kappa \mathrm{B}$ signaling in the granulosa cells of PCOS patients. J Clin Endocrinol Metab 100: 201-211, 2014

40. Hu G, Huang X, Zhang K, Jiang H and Hu X: Anti-inflammatory effect of B-type natriuretic peptide postconditioning during myocardial ischemia-reperfusion: involvement of PI3K/Akt signaling pathway. Inflammation 37: 1669-1674, 2014. 